\title{
Technical Efficiency of Cassava Production in Ardo-Kola Local Government Area of Taraba State, Nigeria
}

\author{
E. A. Zubairu ${ }^{1, *}$, A. D. Kasari ${ }^{2}$, and A. A. U. Jongur ${ }^{3}$ \\ ${ }^{1}$ Department of Agricultural Economics and Extension, Taraba State University \\ Jalingo, Nigeria \\ ${ }^{2}$ Opposite Balfa Lodge Magami, Jalingo \\ Taraba State, Nigeria \\ ${ }^{3}$ Department of Agricultural Economics and Extension, Modibbo Adama University of Technology \\ Yola, Nigeria \\ *Corresponding author's email: zubairuemmanuel [AT] gmail.com
}

\begin{abstract}
This study used stochastic frontier Analysis to estimate the technical efficiency of cassava production in Ardo-kola Local Government Area of Taraba state. A multi-stage sampling was employed in selecting 142 respondents in the study area. The maximum likelihood estimates of the stochastic frontier production function revealed that farm size, family labour, cassava cutting planting and fertilizer were significantly and positively related to cassava output. Technical efficiency (TE) scores ranged from 0.43 to 0.96 with a mean TE of 0.74 , implying that there is a scope for increasing technical efficiency in cassava production by 0.26 in short run under current technology. The study proffered the following recommendations; That Cassava farmers should have access to extension agents to increase their probability of being productive and efficient, policy should be targeted to provide adequate training to extension agents to enhance their performance to their clientele.
\end{abstract}

Keywords: Technical efficiency; cassava production; stochastic frontier production

\section{INTRODUCTION}

Cassava (Manihot esculentus) is among the major staple food crops in Nigeria, it is an excellent source of carbohydrate and the most widely cultivated crop in the southern part of Nigeria in terms of hectare and number of farmers growing it. Nigeria is the largest producer of cassava in the world and production of cassava is put at about 34 metric tonnes a year [1]. Indeed, it is widely grown by millions of household in Nigeria [2]. Cassava can be grown on a wide range and can yield satisfactorily even in acidic soils where most other crops fails [3]. The crop has continually played very vital roles, which include a major source of income to farmers, low cost food source for household food security and employment for rural households in Nigeria [4]. The crop has achieved an export status because of the increasing demand for it as industrial raw material and there is an increase in Cassava production since 2009 which might be due to this intervention and if well harnessed, it would be next to petroleum in GDP contribution [5]. But in Nigeria, Cassava is generally believed to be cultivated by small scaled farmers with low resources [6]. However, cassava farms just like the other crop farmers are characterized by very low productivity which is a crucial issue in the Nigerian agriculture.

The problem of declining crop productivity in Nigerian agricultural sector is revolved around the efficiency with which farmers use resources on their farms. Despite all human and material resources devoted to agriculture, the productive efficiency for most crops still fall under 60 per cent [7]. Also technical efficiency implies the ability of a firm to obtain maximum output from the given inputs. It is the ratio of output to input and the greater the ratio, the more the magnitude of technical efficiency [8].

\section{Conceptual Framework and Empirical Review}

Stochastic production frontier Model It is a parametric technique that uses standard production function methodology used to estimate production or cost functions in economics, while explicitly accounting for the existence of firm inefficiency [9]. The stochastic production frontier consists of a production function with a composite error term equal to the sum of two error components. The first error component, also called a statistical or white noise, accounts for random effects. The second component represents systematic effects that are not explained by the production function but 
attributed to technical inefficiency. Stochastic production frontier (SFA) produces efficiency estimates or efficiency scores of individual producers. Thus one can identify those who need intervention and corrective measures [10].

Efficiency according to [11] refers to the ability of a producing unit to obtain maximum (optimal) output from a given amount of inputs. Farm production efficiency is the ability of a farm to produce a given level of output with the lowest amount of resources. The efficient method of producing a product is the one which uses the least amount of resources to get a given amount of output [12]. A technically efficient farm operates on the production frontier while a technically inefficient farm operates below the frontier and could be made efficient by increasing its output with the same input level or using fewer inputs to produce the same level of output. As such, the closer a farm gets to the frontier the more technically efficient it becomes [13]. Technical efficiency in production is the physical ratio of output to the factor input. Technical efficiency is a principal element in economic profitability as it measures the ability of the firm to produce maximal output from a given set of inputs [14].

[15] Used the Stochastic Frontier Production Function to determine the Productivity and Efficiency of Groundnut Farming in Northern Taraba State. The result revealed that the variance of parameters gamma $(\gamma)$ and sigma-squared $(\delta 2)$ of the frontier production function were statistically significant at 1 percent level of significance. The variables indicate positive and significant at 10 percent level of significance for seed and fertilizer, while farm size and family labour were statistically significant at 1 percent respectively. The positive and significant relationship between farm size, seed, fertilizer and family labour indicate that if more of these variables are used in groundnut farming, there will be more than proportionate increase in the output of groundnut.

[16] Determined the Technical Efficiency of Sorghum Production in Hong Local Government Area of Adamawa State, Nigeria. The Stochastic Frontier Production Model revealed that the technical efficiencies of the sample sorghum farmers were less than one. The predicted farm specific technical efficiency for the farmers ranged from 0.15 to 0.92 with a mean technical efficiency of 0.72 . This imply that in the short run, there is scope for increasing sorghum production by about $28 \%$ by adopting the technology and techniques used by the best practice farmer.

\section{METHODOLOGY}

The study was conducted in Ardo-kola Local Government Area of Taraba state. The Local government is one of the sixteen (16) local government areas of Taraba state and has an estimated population of about 86,921 and the present projected population of 2015 is 106,964 [17]. It has a total land area of about $2,262 \mathrm{~km}^{2}$ and located between latitudes $8^{\circ} 34^{\prime}$ and $9^{\circ} 10^{\prime}$ and longitudes $10^{\circ} 58^{\prime}$ and $11^{\circ} 30^{\prime}$ East of the Greenwich meridian. The Local government headquarters lies $24 \mathrm{kms}$ away from Jalingo the state capital. It's bordered to the east by Jalingo, Gassol to the west, and Karim-Lamido to the North and Bali local government area to the south.

The climate of the local government area is marked by dry season between (November-March) and rainy season between (April-October).It has an average annual rainfall of between $800 \mathrm{~mm}$ to $1,525 \mathrm{~mm}$ and temperature variation between $15^{\circ}$ to $38^{\circ}$. The agrarian nature and rich alluvial track of soil found in most part of the local government makes the local government area conducive for growing of various food crops like rice, maize, Cassava, sorghum, yam among others with majority of inhabitants of the local government area are engage in farming as an occupation. The basic amenities available are schools, hospitals, electricity and communication service among others. Some of the economic activities in the local government area are; fishing, pottery, cloth weaving among others. It also has various ethnic groups which include; Jukun-Kona, Mumuye, Fulani among others [18].

\section{Source of Data and Method of Data Collection}

The data for this study were obtained mainly from primary sources. This was obtained by the use of structured questionnaire which were administered to Cassava farmers in the study area.

\section{Sampling procedure}

A multi-stage sampling technique was used in selecting the respondents for the study. Firstly, five (5) wards were selected out of the ten (10) wards in the Local Government Area selected for the study. Second stage sampling involved a purposive selection of two (2) villages in each of the selected wards to give a total of ten villages. From the ten villages, a total of 150 cassava farmers were randomly selected in proportion to the size of the villages. However, only 142 questionnaires were returned with useful information, hence were used for the study.

\section{Analytical Techniques}

Inferential statistics were employed in the analysis of data collected. The tool used was maximum likelihood estimate (MLE) for all parameters of the stochastic frontier production function and the inefficiency model for the cassava farmers in the study area. 


\section{The stochastic frontier production model}

The SFP model was employed to estimate the technical efficiency of cassava farmers in in the study area. This is in the form of the Coelli and Battese inefficiency model. The model overcomes the deficiency of the deterministic production function employed by earlier studies with parameters computed using mathematical programming techniques, inadequate characteristics of the assumed error term, and has an inherent limitation on the statistical inference on the parameters and resulting efficiency estimates. The stochastic frontier model is specified as;

$\mathrm{Y}_{\mathrm{i}}=f\left(\mathrm{X}_{\mathrm{i}} ; \beta_{\mathrm{i}}\right) \exp (\mathrm{Vi}-\mathrm{Ui}), \mathrm{i}=1,2 \ldots \mathrm{n}$

Where

$Y_{i}=$ output of the ith farm,

$\mathrm{X}_{\mathrm{i}}=$ vector of input quantities whose values are functions of inputs and other explanatory variables for the ith farm

$\beta_{\mathrm{i}}=$ vector of unknown parameters to be estimated

$f\left(\mathrm{X}_{\mathrm{i}} ; \beta_{\mathrm{i}}\right)=$ is the production frontier

$\mathrm{Vi}=$ symmetric error which accounts for random variation in output due to factors beyond the control of the farmer e.g. weather, disease outbreaks

$\mathrm{Ui}=$ non-negative random variable representing inefficiency in production relative to the stochastic frontier.

The random error $\mathrm{Vi}$ is assumed to be independent and identically distributed $\mathrm{N}\left(0, \sigma^{2} \mathrm{v}\right)$ random Variables independent of the $\mathrm{Uj}$ which are assumed to be non-negative truncation of the $\mathrm{N}\left(0, \sigma^{2} \mathrm{v}\right)$ distribution (i.e. half-normal distribution) or have exponential distribution [19].

The technical efficiency of an individual farmer is defined in terms of the ratio of the observed output to the corresponding frontier output given the available technology [20].

Technical efficiency $(\mathrm{TE})=\mathrm{Y}_{\mathrm{i}} / \mathrm{Y}_{\mathrm{i}}^{*}$

Where;

$\mathrm{Y}_{\mathrm{i}}=$ observed Output

$\mathrm{Y}_{\mathrm{i}}^{*}=$ Frontier Output

$=f\left(\mathrm{X}_{\mathrm{i}}, \beta_{\mathrm{i}}\right) \exp \left(\mathrm{V}_{\mathrm{i}}-\mathrm{U}_{\mathrm{i}}\right) / f\left(\mathrm{X}_{\mathrm{i}}, \beta_{\mathrm{i}}\right) \exp \left(\mathrm{V}_{\mathrm{i}}\right)$

$=\exp \left(-\mathrm{U}_{\mathrm{i}}\right)$

So that $0<\mathrm{TE}<1$,

$\mathrm{U}_{\mathrm{i}}>0 . \mathrm{Y}_{\mathrm{i}}$ will achieves its maximum feasible value of $\mathrm{f}\left(\mathrm{X}_{\mathrm{i}} ; \beta\right) \exp (\mathrm{Vi})$ if and only if $\mathrm{TE}=1$, otherwise $\mathrm{TE}<1$ provides a measure of the shortfall of the observed output from the maximum feasible output.

The empirical model that will be use to determine the technical efficiency of cassava farmers is defined as:

$\mathrm{LnY}=\beta_{0}+\beta_{1} \operatorname{In} X_{1}+\beta_{2} \operatorname{In} X_{2}+\beta_{3} \operatorname{In} X_{3}+\beta_{4} \operatorname{In} X_{4}+\beta_{5} \operatorname{In} X_{5}+\beta 6 \operatorname{InX} 6+V i-U$.

Where:

$\mathrm{Ln}=$ denote natural logarithm.

$\mathrm{Y}=$ Cassava output $(\mathrm{kg})$

$\mathrm{X}_{1}=$ Farm size (hectares)

$\mathrm{X}_{2}=$ Hired labour (man days)

$\mathrm{X}_{3}=$ Family labour (man days)

$\mathrm{X}_{4}=$ Quantity of cassava cuttings planted (bundles)

$\mathrm{X}_{5}=$ Quantity of agrochemicals used in liters 
$\mathrm{X}_{6}=$ Quantity of Fertilizers used in kilograms

$\mathrm{V}_{\mathrm{i}}=$ random variability in the production that cannot be influenced by the farmer;

$\mathrm{U}_{\mathrm{i}}=$ deviation from maximum potential output attributable to technical inefficiency.

$\beta_{0}=$ intercept;

$\beta=$ Vector of production function parameters to be estimated;

But the technical inefficiency effect model is described as;

$\mu_{\mathrm{i}}=\delta_{0}+\delta_{1} \mathrm{Z}_{1}+\delta_{2} \mathrm{Z}_{2}+\delta_{3} \mathrm{Z}_{3}+\delta_{4} \mathrm{Z}_{4}+\delta_{5} \mathrm{Z}_{5}+\mathrm{e}_{\mathrm{i}}$

Where;

$\mu_{\mathrm{i}}=$ technical inefficiency effect of the $\mathrm{i}^{\text {th }}$ farm;

$\mathrm{Z}_{1}=$ Age of farmers in years

$\mathrm{Z}_{2}=$ Years of farming experience

$\mathrm{Z}_{3}=$ Years of formal education

$\mathrm{Z}_{4}=$ Extension contact (number of meetings)

$\mathrm{Z}_{5}=$ Household size (number of people)

$\mathrm{Z}_{6}=$ Credit availability (one for those that have access to credit and zero otherwise)

$\delta=$ parameters to be estimated.

$\mathrm{e}_{\mathrm{i}}=$ random disturbance following half-normal distribution

\section{RESULTS AND DISCUSSION}

\section{Resource Productivity}

The maximum likelihood (MLE) estimates of the stochastic frontier production for cassava farmers are given in Table 1. Four (4) of the production factors in the function are statistically significant at different levels; there are farm size, family labour, cassava cuttings planted and fertilizer. The value of gamma was 0.869 and statistically significant at $1 \%$ level indicating that $86.9 \%$ of variation in cassava output was as a result of the technical inefficiency of the cassava farmers. In other words, due to factors beyond the farmers control (outbreak, weather, disaster, disease etc) but also occasioned by error due to the technical inefficiency of the farmers in production. This means that there is the presence of technical inefficiency in the production of cassava by the farmers. Also, the sigma squared value was statistically significant at $1 \%$ level. This implies a good fit of the model used, and that the conventional production function is not an adequate representation of the data. The coefficient of farm size is 0.283 and has a positive sign; signifying that a unit increase of farm size added to what was obtainable could lead to a major increase in yield of cassava of up to $0.283 \%$. This means that farm size is a significant determinant of output of cassava.

Family labour has an elasticity efficiency of 0.189 and is positively related to the total output of cassava. A 5 percent increase in family labour will bring about an increase in the level of output. The quantity of cassava cuttings planted was statistically significant at 5\% level, and had a positive effect on the output of cassava. This means that the output of cassava produced by farmers improves as the amount of cassava cuttings planted used increases

Furthermore, the result showed that fertilizer was statistically significant at 5\% level. The coefficient of fertilizer (0.094) was positive in conformity to the aprior expectation. This means that the output of cassava increases with rise in the amount of fertilizer used by the cassava farmers and vice-versa.

The result of the inefficiency model shows the analysis of farmer specific variable which include age, farming experience, education, extension contact, family size and credit availability. However, the interpretation is in opposite direction, that is, if the coefficient of a parameter is positive for instance, it means the variable has negative impact on technical efficiency of the farmers in production. 
The age of farmers was statistically significant at $1 \%$ level and had a greater influence on the technical efficiency of farmers. This means that the technical efficiency of farmers increase with rise in the farmers age. In other words, older farmer tend to be more technically efficient than the younger one.

The coefficient of farming experience is statistically significant at $1 \%$ and carries a negative sign. This implies that more years of experience enhance farmer's efficiency in production because farmers with many years of experience will know how to handle various farming operation than farmers with few years of experience and this will have a significant effect on their level of the output.

Educational level of cassava farmers was shown to be statistically significant at 5\% level and had a great influence on the technical efficiency of the cassava farmers. Educated farmers will be able to readily adopt and utilize efficiently modern technologies which results in higher productivity.

Table 1 Maximum Likelihood Estimates of the Parameters of the Stochastic Frontier Production Function

\begin{tabular}{lllll}
\hline Variable & Parameter & Coefficient & $\begin{array}{l}\text { Standard } \\
\text { error }\end{array}$ & t-ratio \\
\hline Production factor & & & & \\
Constant & $\beta_{0}$ & 2.813 & 0.754 & $3.730^{*}$ \\
Farm size $\left(\mathrm{X}_{1}\right)$ & $\beta_{1}$ & 0.283 & 0.091 & $3.095^{*}$ \\
Hired labour $\left(\mathrm{X}_{2}\right)$ & $\beta_{2}$ & -0.042 & 0.062 & -0.686 \\
Family labour $\left(\mathrm{X}_{3}\right)$ & $\beta_{3}$ & 0.189 & 0.093 & $2.032^{* *}$ \\
Quantity of cassava cuttings planted $\left(\mathrm{X}_{4}\right)$ & $\beta_{4}$ & 0.138 & 0.056 & $2.482^{* *}$ \\
Quantity of agrochemicals used $\left(\mathrm{X}_{5}\right)$ & $\beta_{5}$ & -0.068 & 0.082 & -0.831 \\
Quantity of Fertilizers used $\left(\mathrm{X}_{6}\right)$ & $\beta_{6}$ & 0.094 & 0.040 & $2.323^{* *}$ \\
& & & & $-2.715^{*}$ \\
Inefficiency Effect & & & & $-2.114^{* *}$ \\
Age $\left(\mathrm{Z}_{1}\right)$ & $\delta_{1}$ & -0.160 & 0.046 & -1.459 \\
farming experience $\left(\mathrm{Z}_{2}\right)$ & $\delta_{2}$ & -0.204 & 0.075 & 0.038 \\
Education $\left(\mathrm{Z}_{3}\right)$ & $\delta_{3}$ & -0.302 & 0.014 & 0.263 \\
Extension contact $\left(\mathrm{Z}_{4}\right)$ & $\delta_{4}$ & -0.033 & 0.023 & $-3.454^{*}$ \\
Household size $\left(\mathrm{Z}_{5}\right)$ & $\delta_{5}$ & 0.024 & 0.629 & $4.748^{*}$ \\
Credit availability $\left(\mathrm{Z}_{6}\right)$ & $\delta_{6}$ & 0.043 & 0.163 & $3.334^{*}$ \\
Diagnostic Statistics & & & \\
Sigma-squared & $\delta^{2}$ & 0.123 & 0.026 & 0.260 \\
Gamma & $\gamma$ & 0.869 & & \\
Log Likelihood & $\mathrm{LLF}$ & 159.40 & & \\
\hline
\end{tabular}

Source: Computer printout from Frontier 4.1

$* * *$ Significant at $1 \%$ level; **Significant at $5 \%$ level

\section{Distribution of Technical Efficiency level of Cassava farmers}

Table 2. Show the distribution of the technical efficiencies of respondents which is derived from the analysis of the stochastic frontier production function. The technical efficiency of the sample cassava farmers is less than 1.00, indicating that cassava farmers in the study area are producing below the maximum efficiency frontier. The best farm has a technical efficiency of 0.96 (96\%) while the worst farm has a technical efficiency of 0.43 . the mean technical efficiency is $0.74(74 \%)$ implying that, on an average the farmers were able to obtain 74 of potential output from a given mix of production inputs. This indicates that in the short run, there is a scope for increasing technical efficiency in cassava production in the study area by 26 percent.

The distribution of technical efficiency of the farmers reveals that about $2.82 \%$ had technical efficiency of less than 50 percent while $35.21 \%$ had technical efficiency of 50-69 percent. However, $61.97 \%$ of the farmers had a technical efficiency of $70 \%$ and above. 
Table 2. Distribution of Technical Efficiency level of Cassava farmers

\begin{tabular}{lll}
\hline Efficiency index & Frequency & Percentage \\
\hline $0.40-0.49$ & 4 & 2.82 \\
$0.50-0.59$ & 24 & 16.90 \\
$0.60-0.69$ & 26 & 18.31 \\
$0.70-0.79$ & 38 & 26.76 \\
$0.80-0.89$ & 34 & 23.94 \\
$0.90-1.00$ & 16 & 11.27 \\
Total & 142 & 100 \\
Mean $=0.74$ & & \\
Minimum $=0.43$ & & \\
Maximum $=0.96$ & &
\end{tabular}

\section{CONCLUSION}

The study concludes that, the maximum likelihood estimates of the stochastic frontier production function revealed that farm size, family labour, cassava cutting planting and fertilizer were significantly and positively related to cassava output. Technical efficiency (TE) scores ranged from 0.43 to 0.96 with a mean TE of 0.74 , implying that there is a scope for increasing technical efficiency in cassava production by 0.26 in short run under current technology.

\section{RECOMMENDATION}

The following recommendations are proffered based on the finding of the study; Cassava farmers that have access to extension agents have higher probability of being productive and efficient, policy should be target to provide adequate training to extension agents to enhance their performance to their clientele, and also easy access to credit facilities in the study area.

\section{REFERENCES}

1. Raphael I.O (2008). Technical efficiency of cassava farmers in south eastern Nigeria: Stochastic frontier approach. Agricultural Journal. 3(2): 152-156.

2. Emokaro, C.O, Ekunwe, P.A and Osawaru, J.I (2010). Profitability and Viability of Cassava Marketing in Lean and Peak Seasons in Benin City, Nigeria. Journal of Applied Science Research. 6 (5): 443-446.

3. Ebukiba, E. (2010). Economic analysis of cassava production (farming) in Akwa Ibom State Agriculture and Biology Journal of North America 2151-7517.

4. Ogundari, K.; Ojo, S,O. and Ajibefun, I.A. (2006). An Examination of Technical, Economic and Allocative Efficiency of Small Farms: The Case Study of Cassava Farmers in Osun State of Nigeria, Journal Central European Agriculture. 7 (3), 423-432.

5. Awoyinka, Y.A (2009). Effect of Presidential Initiative on Cassava Production Efficiency in Oyo State, Nigeria. OZean Journal of Applied Science. 2(2):185-193.

6. Ezebuiro, N.O, Chukwo, G.O, Okoye, B.C, Oboagjs, I.C (2008). Policy Issue and Adoption of improved Cassava Varieties; Gender Consideration in Umuahia Zone of Abia State.1056-1059.

7. Ebong, V. O, Effiong E.O; Eshiet A.J and Hope Nuka (2011) Resource use efficiency of landowners and tenants in cassava based farms in Akwa Ibom State, Nigeria: A comparative analysis. Agriculture and Biology Journal of North America.

8. Simonyan, J. B., Olukosi, J. O., Omolehin, R. A. and Atala, T. K. A., (2012).Productivity and Technical Efficiency among Beneficiary Farmers of Second National Fadama Project in Kaduna State, Nigeria. American Journal of Experimental Agriculture 2(1): 102 - 110.

9. Coelli. T. J., Rao, D. S. P., and Battese, G. E. (1998). An Introduction to Efficiency and Productivity Analysis, Kluwer Academic Publishers. Boston. USA. 
10. Zubairu, E.A and Maurice, D.C (2014). Analysis of Household Food Insecurity Among Food Crops Farmers in Ardo- Kola Local Government Area of Taraba State, Nigeria, Taraba Journal of Agriculture Research.2(2): 2225

11. Henderson, D. (2003). The Measurement of Technical Efficiency Using Panel Data. Mimeo, State University of New York At Binghamton, New York.

12. Ogunyinka, E.O. and Ajibefun, I.A. (2003). Determinants of Technical Inefficiency of Farm Production: Tobit Analysis Approach to the NDE Farmers in Ondo State, Nigeria. International Journal of Agriculture and Biology, 6 (2): 355-358.

13. Rahman, S. A.; Ajayi. F. A. and Gabriel, J. (2005). Technical Efficiency in Sorghum-based Cropping Systems in Soba Area of Kaduna State, Nigeria. Journal of Research in Science and Management, 3(1): 100-104.

14. Giroh, D.Y (2012). Efficiency of Latex Production and Labour Productivity in Rubber Plantation in Edo and Delta State, Nigeria. Unpublished Doctoral Thesis Department of Agricultural Economics and Extension, Modibbo Adama University of Technology, Yola Nigeria. PP 101

15. Taphee, G.B and Jongur, A.A.U (2014) Productivity and Efficiency of Groundnut Farming i n Northern Taraba State, Nigeria. Journal of Agriculture and Sustainability. Volume 5, Number 1, 2014, 45-56.

16. Abba Mohammed Wakili, (2012) Technical Efficiency of Sorghum Production in Hong Local Government Area of Adamawa State, Nigeria. Russian Journal of Agricultural and Socio-Economic Sciences, No. 6(6). Pp 10-15

17. National Population Commission (NPC) (2006). Population Census 2006.

18. Taraba State Government Diary (2010): Taraba State Official Diary, Government Printer Jalingo, Nigeria. Taraba state printing press. Pp $25-29$.

19. Aigner, D.J., Lovell, C.A.K., Schmidth, P.J. (1977). Formulation and Estimation of Stochastic Frontier Production models. Journal of Econometrics, 6(1), 21-38.

20. Onyenweaku, C.E and Effiong, E.O (2008) Technical Efficieny in Pig Production in Akwa-Ibom State, Nigeria, paper presented at the $40^{\text {th }}$ Annual Conference of the Agricultural Society of Nigeria held at NRCRI, Umudike 